\title{
Advocating the Use of Absorbable Sutures for Columellar Incisions Following Open Rhinoplasty
}

\author{
I. Beegun ${ }^{1} \cdot$ H. A. Saleh ${ }^{1}$
}

Received: 12 December 2016/Accepted: 25 January 2017/Published online: 15 February 2017

(C) Springer Science+Business Media New York and International Society of Aesthetic Plastic Surgery 2017

\begin{abstract}
Rapidly absorbable skin sutures have been found to be of use in numerous settings including for the closure of the columellar incision following open rhinoplasty. Its removal does not routinely require trimming, and the sutures tend to fall off with minimal intervention 10-14 days postoperatively. This practice has a good acceptance by patients and utilises less resources in the follow-up period.

Level of evidence IV This journal requires that authors assign a level of evidence to each article. For a full description of these Evidence-Based Medicine ratings, please refer to the Table of Contents or the online Instructions to Authors www.springer.com/00266.
\end{abstract}

Keywords Open rhinoplasty · Inverted-V incision ·

Transcolumellar incision · Columella Absorbable sutures . Non-absorbable sutures $\cdot$ Scar visibility

To the Editor,

We acknowledge the excellent study by Alinasab and Haraldsson [1] and the letter in response to the article by Choudhary et al. [2]. Our unit has also experienced excellent outcomes with the use of absorbable sutures for the closure of the columellar incision during rhinoplasty cases. The senior author (HS) has adopted the use of Vicryl

I. Beegun

drbeegun@gmail.com

H. A. Saleh

h.saleh@imperial.ac.uk

1 Department of Ear Nose and Throat Surgery, Charing Cross Hospital, Imperial College Healthcare NHS Trust, Fulham Palace Road, London W6 8RF, UK rapide $^{\mathrm{TM}}$ since 2010. We have undertaken over 300 open rhinoplasty cases using these sutures and have not detected any complications as a result. The senior author has also regularly used it for skin closure after alar base reduction.

In our unit, we use 6.0, cut the suture short and do not advocate trimming. As per Choudhary et al., we also find that these sutures fall out of their own accord with minimal intervention.

We have conducted a study comparing the scar after the use absorbable versus non-absorbable sutures and found no significant difference (unpublished data). We can confirm the outcomes reported and would advocate the use of absorbable sutures.

\section{Compliance with Ethical Standards}

Conflict of interest The authors declare that they have no conflicts of interest to disclose.

\section{References}

1. Alinasab B, Haraldsson PO (2016) Rapid resorbable sutures are a favourable alternative to non-resorbable sutures in closing transcolumellar incision in rhinoplasty. Aesthet Plast Surg 40:449-452

2. Choudhary S, Khanna S, Mantri R, Arora P, Jain R (2016) Rapidly resorbable skin sutures: story retold! Aesthet Plast Surg. doi:10. 1007/s00266-016-0717-7 